\title{
Synergy between Antifreeze Proteins is Driven by Complementary Ice-Binding
}

Tehilla Berger ${ }^{1}$, Konrad Meister $^{2}$, Arthur L. DeVries ${ }^{3}$, Robert Eves ${ }^{4}$, Peter L. Davies ${ }^{4}$ and Ran Drori*1

${ }^{1}$ Chemistry and Biochemistry Department, Yeshiva University, New York, NY 10016, USA, ${ }^{2}$ Max-Planck Institute for Polymer Research, D-55128 Mainz, Germany, ${ }^{3}$ Department of Animal Biology, University of Illinois, Urbana, Illinois 618010, USA ${ }^{4}$ Department of Biomedical and Molecular Sciences, Queen's University, Kingston, Ontario K7L 3N6, Canada

*Corresponding author: rdrori@yu.edu

\section{Supporting Information}

1. Figure $\mathrm{S} 1$ - TH activity of pure $\mathrm{AF}(\mathrm{G}) \mathrm{Ps}$ presented using a molar basis.

2. Dynamic light scattering (DLS) experiments (Figure S2).

3. Figure S3 - TH activity of a mixture of AFGP $2,3,4$ and AFPIII-QAE.

4. Figure S4 - Measurement of distance between macrosteps in two ice crystals.

5. Figure S5 - Ice crystals in a pure AFPIII-QAE and AFPIII-SP solutions.

6. Table S1 - Calculation of the combination index in mixtures of AFPIII-SP and other AFPs.

7. Table $\mathrm{S} 2$ - Calculation of the combination index in mixtures of AFPIII-QAE and AFGP $2,3,4$.

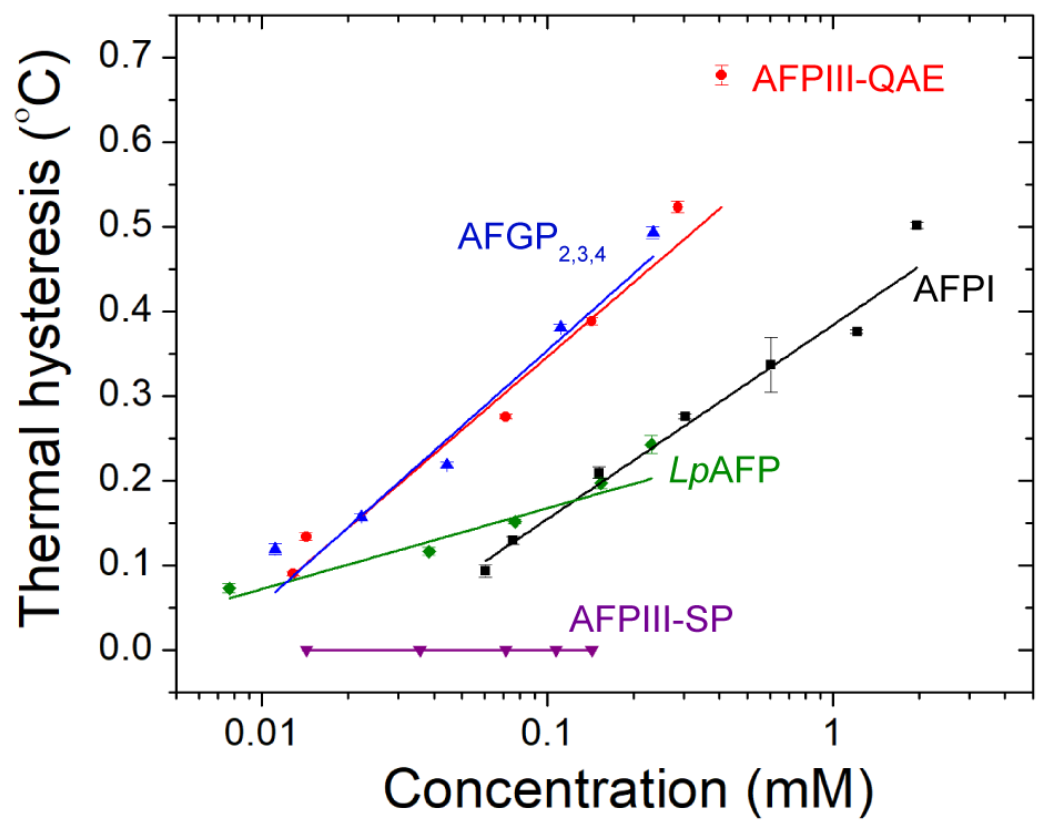

Fig. S1 - TH activity of pure AF(G)Ps and mixed $A F(G) P s . ~ T H$ of the pure $A F(G) P s$ as shown in Fig. 1, presented using a molar basis. Each data point is an average of 5 measurements, error bars indicate standard error. 


\section{$\underline{\text { Dynamic light scattering (DLS) experiments }}$}

Light scattering measurements were performed on an ALV spectrometer consisting of a goniometer and an ALV-5004 multiple-tau full-digital correlator (320 channels), which allows measurements over an angular range from $30^{\circ}$ to $150^{\circ}$. A He-Ne Laser (wavelength of $632.8 \mathrm{~nm}$ ) was used as light source. Measurements were performed at $20{ }^{\circ} \mathrm{C}$ at 9 angles ranging from $30^{\circ}$ to $150^{\circ}$. The hydrodynamic radii $\left(\mathrm{R}_{\mathrm{h}}\right)$ of $1 \mathrm{mg} / \mathrm{ml}$ $\mathrm{AFGP}_{1-5}$ in water and of the mixture 1 $\mathrm{mg} / \mathrm{ml} \mathrm{AFGP} \mathrm{A}_{1-5}+1 \mathrm{mg} / \mathrm{ml}$ AFPIII were determined using dynamic light scattering (DLS). The $\mathrm{R}_{\mathrm{h}}$ of $\mathrm{AFGP}_{1-5}$ in the presence of AFPIII was found to be similar to that of $\mathrm{R}_{\mathrm{h}}$ of $\mathrm{AFGP}_{1-5}$ in water. This observation provides clear evidence that no complex formation between AFPIII and AFGP $_{1-5}$ occurs in solution.

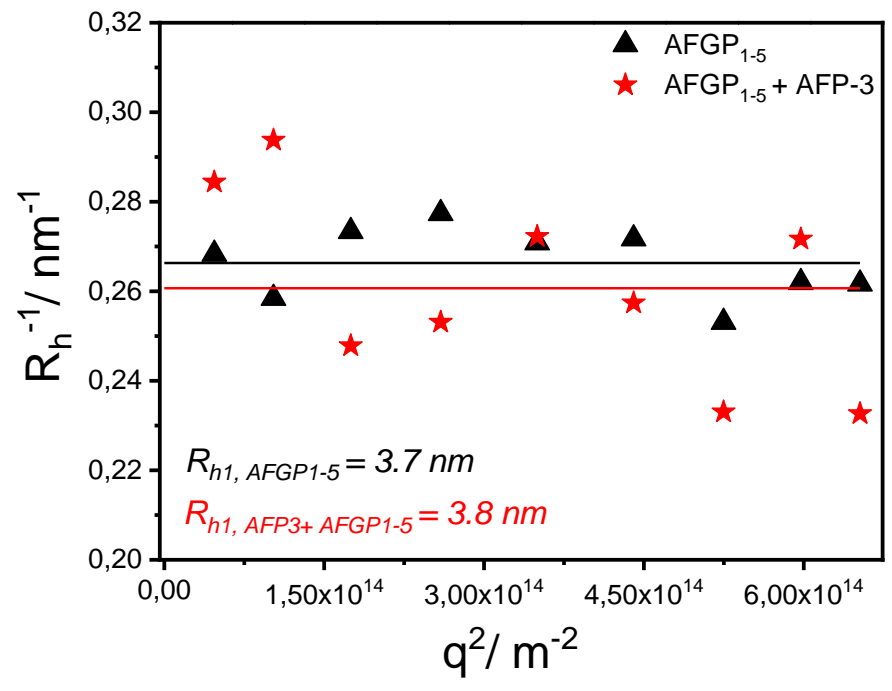

Fig. S2 - Hydrodynamic radii of $\mathrm{AFGP}_{1-5}$ in water and in the presence of AFP-3. The radii are very similar which excludes the possibility of complex formation in solution.

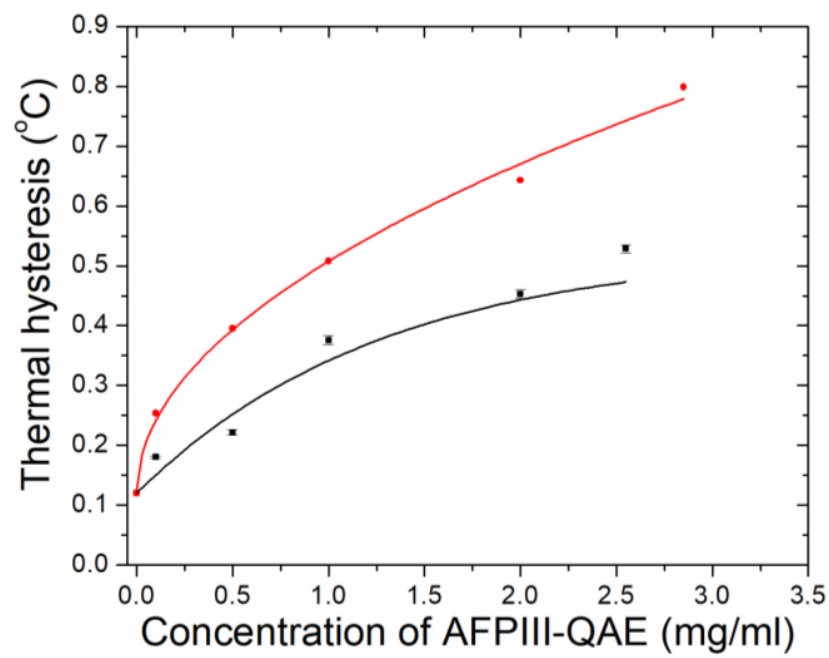

Fig. S3 - TH activity of a mixture of $\mathrm{AFGP}_{2,3,4}(0.25 \mathrm{mg} / \mathrm{ml})$ and different concentrations of AFPIII-QAE (black squares) and the expected TH activity of that mixture (red circles). The expected TH activity is the sum of $\mathrm{TH}$ activities from the two $\mathrm{AF}(\mathrm{G}) \mathrm{Ps}$ at each concentration. This is an example of competitive binding of two $A F(G) P s$ that bind to the prism plane with similar adsorption rates. Each data point is an average of 5 measurements, error bars indicate standard error. 

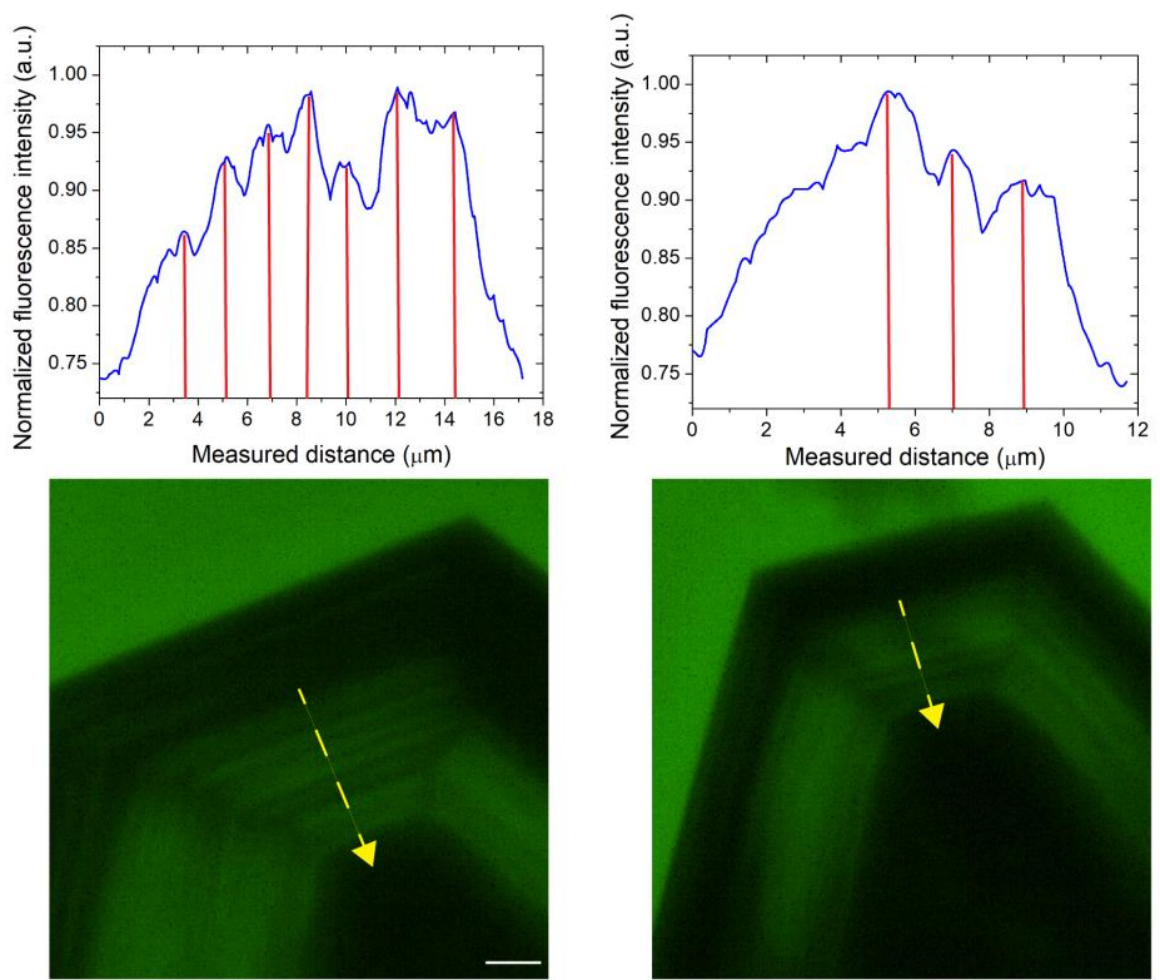

Fig. S4 - The distance between macrosteps was measured for two crystals (Fig. $3 \mathrm{D}$ and $3 \mathrm{~F}$ ) and found to be constant, averaging $1.83 \pm 0.66 \mu \mathrm{m}$ (left) and $1.7 \pm$ $0.2 \mu \mathrm{m}$ (right). Scale bar $=5 \mu \mathrm{m}$.
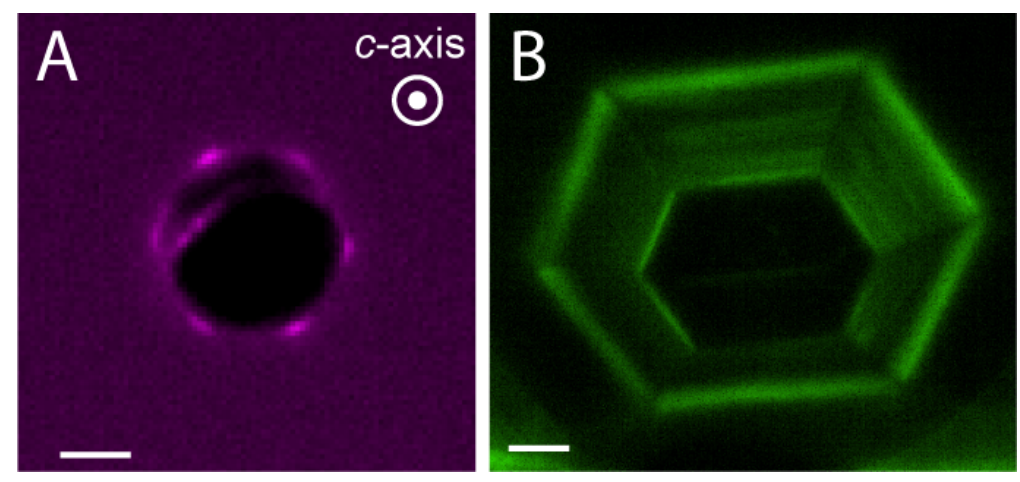

Fig. S5 - Ice crystals in a pure AFPIII-QAE solution (A, 0.028 $\mathrm{mg} / \mathrm{ml}$ ) and AFPIII-SP solution (B, $0.125 \mathrm{mg} / \mathrm{ml})$. These images of the pure isoforms show similar binding locations as shown for the mixture of these two isoforms (Fig. 3). AFPIII-QAE accumulate on the edges of the crystal, while AFPIII-SP binds to pyramidal planes and does not bind to the crystal edges. Scale bar $=10 \mu \mathrm{m}$. 
Table S1 - Calculation of the combination index in mixtures of AFPIII-SP and other AFPs

\begin{tabular}{|c|c|c|c|c|c|}
\hline AFP type & $\begin{array}{l}\text { Conc. Of AFPIII- } \\
\text { SP in the mixture } \\
\qquad(\mathrm{mg} / \mathrm{ml})\end{array}$ & $\begin{array}{c}\text { Conc. Of active } \\
\text { AFP in the } \\
\text { mixture }(\mathrm{mg} / \mathrm{ml}) \\
\left(\mathrm{C}_{1 \mathrm{mix}}\right)\end{array}$ & $\begin{array}{l}\text { TH of } \\
\text { mixture } \\
\quad\left({ }^{\circ} \mathrm{C}\right)\end{array}$ & $\begin{array}{c}\text { Conc. of pure } \\
\text { active isoform with } \\
\text { TH equivalent to } \\
\text { TH of mixture } \\
(\mathrm{mg} / \mathrm{ml})\left(\mathrm{C}_{1 \text { pure }}\right)\end{array}$ & $\begin{array}{l}\text { Combination } \\
\text { index } \\
\left(\mathrm{C}_{1 \text { mix }} / \mathrm{C}_{1 \text { pure }}\right)\end{array}$ \\
\hline $\begin{array}{l}\text { AFPIII- } \\
\text { QAE }\end{array}$ & 1 & 0.09 & 0.9 & 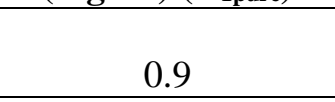 & 0.1 \\
\hline LpAFP & 1 & 0.5 & 0.26 & 3 & 0.17 \\
\hline $\mathrm{AFGP}_{2,3,4}$ & 1 & 0.25 & 0.37 & 2.5 & 0.1 \\
\hline AFPI & 1 & 0.2 & 0.11 & 0.2 & 1.0 \\
\hline
\end{tabular}

Table S2 - Calculation of the combination index in mixtures of AFPIII-QAE and AFGP $2,3,4$

\begin{tabular}{|c|c|c|c|c|c|c|}
\hline AFP type & $\begin{array}{c}\text { Conc. Of } \\
\text { AFPIII- } \\
\text { QAE } \\
(\mathbf{m g} / \mathbf{m l}) \\
\left(\mathbf{C}_{2 \mathrm{mix}}\right)\end{array}$ & $\begin{array}{l}\text { Conc. Of } \\
\text { AFGP }{ }_{2,3,4} \text { in } \\
\text { the mixture } \\
(\mathrm{mg} / \mathrm{ml}) \\
\left(\mathrm{C}_{1 \mathrm{mix}}\right)\end{array}$ & $\begin{array}{c}\text { TH of } \\
\text { mixture } \\
\left({ }^{\circ} \mathrm{C}\right)\end{array}$ & $\begin{array}{c}\text { Conc. of } \\
\text { AFGP } 2,3,4 \\
\text { with TH } \\
\text { equivalent } \\
\text { to TH of } \\
\text { mixture } \\
\text { (mg/ml) } \\
\text { (C } 1 \text { pure })\end{array}$ & $\begin{array}{c}\text { Conc. of } \\
\text { pure } \\
\text { AFPIII- } \\
\text { QAE with } \\
\text { TH } \\
\text { equivalent } \\
\text { to TH of } \\
\text { mixture } \\
\text { (mg/ml) } \\
\left(\mathrm{C}_{2 \text { pure }}\right) \\
\end{array}$ & $\begin{array}{c}\text { Combination } \\
\text { index } \\
\left(\mathbf{C}_{1 \text { mix }} / \mathbf{C}_{1 \text { pure }}\right)+ \\
\left(\mathbf{C}_{2 \text { mix }} / \mathbf{C}_{2 \text { pure }}\right)\end{array}$ \\
\hline $\mathrm{AFGP}_{2,3,4}$ & 2.55 & 0.25 & 0.53 & 5 & 2 & 1.325 \\
\hline
\end{tabular}

